SHS Web of Conferences 6, 01014 (2014)

DOI: $10.1051 /$ shsconf / 20140601014

(C) Owned by the authors, published by EDP Sciences, 2014

\title{
Discussion on Farmer Flow from the Perspective of Economic Benefits
}

Jia Fenfen

Institute of Political Science, China West Normal University, 637009 Nanchong Sichuan, China.

\begin{abstract}
Market economy is the major carrier of current economic development. Market economy functions not only as the decisive factor guiding the change of social structure, but also as the promoter and guider of the nation's modernization. By observation and comparison, the author of this paper believes that economic benefit as the essential role causes the migration of the farm laborers, it is the factor that causes the migration and finally decides the result of the migration. Economic development changed the agricultural status and the village. This change brought the villagers flow and the villager flow promoted the economic development. All of the change brings the social transformation to have profound influence. On the other hand, the spontaneous villagers flow has brought the trouble to social governance and other aspects and cannot make economic development adapt to the human resources. We should provide the migrant workers with dynamic management and reduce the villagers flow. We must guide the development of migrant workers reasonably to resolve the problem with the villagers flow.
\end{abstract}

Keywords. economic benefits; migrant workers; farmer flow

In economic development, market economy is the major carrier of economic development which promotes social changes. It is not only a decisive factor in guiding social pattern change, but also the promoters and the guider which makes China move towards modernization. After the reform and opening, the market environment and the rural system of our country has changed. The changes and interaction between the market environment and the rural system lead the development of the society in China and then drive China's whole pattern changes. The development of market economy makes the original system of curing in our economy, politics, lifestyle and other factors gradually melted and resources and other factors gradually circulation to provide drive forces and dynamic rule environment for modernization revolution of society of China. The rural change lies in the implementation of household contract responsibility system. This policy makes the toughening rural social life dynamic and free from the original single politic life of villagers to be free body and provides human resources and following power for development of market economy.

Urban development and the gradual flow of economic resources gradually expand and diversify the city, and require a lot of population for expansion and creation of wealth. It is well known that the gap between urban and rural areas in the wave of entire economy shows the phenomenon of hollow shell of the village and even hollow village due to the rapid growth of rural migrant workers. Thus, This is an Open Access article distributed under the terms of the Creative Commons Attribution License 2.0, which permits unrestricted use, distribution, and reproduction in any medium, provided the original work is properly cited. 
vast majority of the villages gradually decline significantly and the population moves in a great degree. On one hand, this pushes rural area to decline; on the other hand, it provides endless power for the rapid urbanization and economic development of our country, in which the role of migrant workers in the urban economy is extremely eye-catching. So it becomes a major power factor to promote China's economic development. However, the extraordinary achievements of migrant workers cannot substitute the problems with migrant workers and villages and other inevitable issues caused by the large flow of migrant workers. Thus, the problems facing China's agriculture, rural areas and farmers are put forward and attract long-term and wide attention. Of such problems, the problems with farmer flow and village development are discussed gradually by the scholars and related outcomes provide valuable guidance for our country to solve rural issues.

In fact, peasant migration is a transfer of a large number of farmers driven by the economic development. In our country, migrant workers flooded in 2006, but this is also an inevitable trend in China's economic development and the largest motivation triggering a series of farmers and rural issues. For the problems with farmer flow, there are sufficient relevant descriptions on cause and problems with farmer flow and difficulties, but and discussion on most essential origins of farmer flow lacks. Through observation, analysis and comparison, the author believes that economic benefits play the most essential role in farmer flow and they are the cause of farmer flow and the factor to finally determine the result, influence and form of farmer flow.

\section{Relation between agriculture status and economic benefits}

Since the ancient times, agriculture is a major and key issues related to people's livelihood. All the wars are caused by food. The food for survival is always the survival guarantee pursued by the nation and farmers and key element to safeguard national unity and stability. The agricultural issues have attracted the emphasis of all dynasties. Since the founding of new China and reform and opening, agriculture is an important factor in maintaining harmony and stability in China, but also a big challenge to solve. Economic development breaks the original solid agricultural monopoly status dominated by primary industry, and gradually increases secondary and tertiary industries, to change the original single economic pattern. The original order of primary, secondary and tertiary industries changes into the order of tertiary, secondary, and primary industries. The change in proportion of economic benefit causes the change in the relation between agriculture and the economy, and ultimately affects the pattern of the entire economy.

\subsection{Relation between national macro-economic benefit and agricultural benefit}

In traditional China, due to the governance philosophy of productivity and more emphasis on agriculture and less emphasis on industry, agriculture is in the dominant status since ancient times. Due to the lagging behind of productivity and overall stability of the country, the agriculture suppressed the commerce. In other words, the agriculture is the basis to develop the county in traditional China and the top priority for the national economy and livelihood of the masses. It can be said that at this time agriculture is the main line of the national economy and an important industry dominating the national economy. The agricultural benefits can almost replace the economic benefit. At that time, agriculture is unique and dominant and it is not only an important criterion for national prosperity or decline, but also the most important work of majority of the population. It can be said that economic benefit was the agriculture at that time.

In modern China, the economic and agricultural benefits no longer seems to be synonymous with each other, but the economic benefits include agriculture, and it plays a promoting or dominant role in agriculture benefits. With the development of the productive forces, particularly productivity outbreak today, it promotes productivity-driven economic development, gets the meaning of economical area and national benefits out of agriculture to become a diverse and efficiency- increasing benefit form. Although there are several major economic crisis, but you cannot deny the fact of rapid development of the whole economy and quick increase in wealth. At this point, the status of agriculture has 
declined due to three technological revolutions to gradually become the end of the three industries. The agricultural benefits could not catch up that in the traditional China. In the whole economy, although it still plays an important role in the national economy and livelihood of the masses, but it is no longer synonymous with the economy, and plays a role or has a position of economic sectors in the economy.

\subsection{Relation between land revenue and survival of farmers}

In traditional China, it is undeniable that not only for the country, but also for the farmers, agriculture is almost the foundation of farmers and the core element of our traditional grassroots of society. "The water that bears the boat is the same that swallows it" means that the native farmers depend on agriculture for a living. At this time in China, attaching import to agriculture and despising commerce as well as taking agriculture as the core form the network of blood-based interpersonal relationship ${ }^{1}$. The immobility of land firmly ties the population to the land. They cultivated day after day and this passed on from generation to generation. At this time, the farmer flow did not exist and they became the native countryman. In the social networks of acquaintances, they helped each other, and landless peasant seemed to be the rootless tramp. At that time, the existence of the land met various needs of daily life of villagers and became the ultimate source of a happy life for villagers.

Since the beginning of reform and opening-up, agricultural benefit has already lost its dominance, it has been impacted in all types of economic elements, and its role in the economy has been gradually reduced. However, the condition of agriculture was obviously related to the country's stability and life of villagers. In the relationship between the farmers and the land, the land was still being considered as the final survival safeguard of farmers. Now, in the transitional period of China's social modernization, the farmers change under the driving of market economy. The foreign exchanges increase and constraint of farmer on land is gradually weakened. The sources of income of the villagers have been diversified, including agricultural income, wage income or operating income. Therefore, the relation between the land and villagers has changed gradually and its dominant position declined gradually, which become the final dependence and ultimate guarantee for life sources of villagers. At this time, the weakening of connection between land and farmers cannot restrain the farmer flow any more, but it is the guarantee that the famers cannot discard and are unable to discard.

\section{Change in economy proportion and difficulty of farmers}

In the economic development, development and changes in the economic structure and factors determine the transformation of the whole society, which is the driving force of change of the whole society and rules creator. Its interaction with government policy shapes the entire society. During the shaping, its strong force will penetrate every corner of society, and drive the social structure of the whole country. The rapid development of economy comes from the occurrence of technological revolution. The huge productivity leads to earth-shaking changes in the whole world. Although the economic development of China was late and lagged to a degree due to various reasons, but its trend of social change will not change and it is also a reference model of social transformation. Current society of China is in a period of economy-driven social change. Since the beginning of reform and opening-up, with strong strength in the 30 years' development, the city forms more mature governance structure. Under such driving force, it plays an increasingly important role in economy development of China. Effective development of the city cannot substitute for the important role of agriculture in national governance. Although the city's development can provide strong support for the transformation of the countryside, in our current environment, the living conditions of countryside and farmers are full of difficulties which become widely-concerned focus. The cause of this phenomenon and its driving force is the changes in China's economy.

${ }^{1}$ Fei Xiaotong, Earthbound China, Reproductive System [M], Beijing: Peking University Press, May 1998, page 24. 


\subsection{Promotion of change in economy proportion}

At present, proportion of China's economy changes and develops rapidly in the order of the tertiary, secondary and primary industries. Although the agriculture continuously grows in long-term development, its growth rate is far behind secondary and tertiary industries because of the responsibility of grain cultivation. For example, the average annual growth of primary industry from 2006 to 2010 was $4.5 \%$, secondary industry $12.1 \%$, and the tertiary industry $11.9 \%{ }^{2}$. This development trend is common for China's economic development. The economic factors change into the trend from agriculture-dominated to diversified status. This is bound to determine the master of changes in the economic benefits to social change and also plays a dominant role in rural development.

It is an inevitable trend that economic development allows the whole society blends in with one. The village must also be a part of the whole society. Then, the closed village will inevitably interact with the whole society to become the economic development participant and competitor with the city. Since the villages as the original rural individuals become the social community to participate in the competition, they will inevitably show their advantages and disadvantages in this competition. Of course, it is well known that "the issue of agriculture, rural areas and peasants" has been widely concerned. It also confirms the rural decline in competition between urban and rural areas from one aspect. The decline of village development has become an inevitable trend.

First of all, the difference in growth rate of proportion widens the gap between urban and rural areas. In rural areas, land is the primary resource of the village, and ultimate guarantee for survival of villagers. As the name implies, the rural area is dominated by the agricultural benefit, i.e. the primary industry. The growth of agricultural income is a common trend, but it is an inevitable law of economic development that its growth rate is far behind the secondary and tertiary industry. The slow growth of agriculture and rapid growth of the secondary and tertiary industry relatively squeeze the primary industry so that relative change in the speed of urban and rural development occurs. Although the agriculture has increased in rural area, the gap between its growth rate and that of urban secondary and tertiary industries is great. This growth gap widens gap between urban and rural areas, making the rural decline gradually. Its great attraction gets all kinds of resources away from the rural areas, especially human resources.

Secondly, structural adjustment promotes population and occupational differentiation. Economic development makes industrial structure of our country to make a major adjustment. The original order of proportion of primary, secondary and tertiary industries change into the order of tertiary, secondary, and primary industries. Thus, decline in agricultural position and rise of position of secondary and tertiary industries inevitably heralds more need of people engaged in secondary and tertiary industries, and the gap of population inevitably gets the rural people out of agriculture. In China's economic structure, the rural areas are dominated by agriculture as the primary industry and cities are dominated by the secondary and tertiary industries. The adjustment of status of traditional agriculture, population and engaged industries will inevitably lead to flow of rural population into the cities due to geography and industry. This is also the root cause of farmer flow and occurrence of and migrant workers.

\subsection{Relation between decline of agricultural benefit and farmer flow}

The driving force of macroeconomic framework and development trends for our society is an important factor in determining the development and evolution of society, and also a strong force to promote change and development in rural areas. In front of the macroeconomic framework, the villages are in extreme disadvantage in competition with cities because of its resources and industries, which determines the development of the village and various aspects of the villagers, especially the crucial impact on the flow of villagers. This the decisive factor in the flow of the villagers and

\footnotetext{
${ }^{2}$ Proportion of tertiary industry during "eleventh five-year plan increases to $443 \%$, with an increase of 2.5\%" [DB/OL]. China News, March 11, 2011.
} 
farmers.

\subsubsection{Macroscopic factor of farmer flow}

Firstly, conflict between economic performance and working population. The current situation in China is developed gradually from traditional agriculture. In the early years of founding, the priority development of heavy industry has some impact on China's economic development, but because of strict stipulation of system of integrating administrative unit with economic entity and household registration system, the agricultural population was strictly limited in rural areas. At this time, peasant migration phenomenon hardly exists in the national environment. After the reform and opening up, relaxed rural environment laid foundation for future rural farmer flow. Meanwhile, changes in proportion agricultural income and the benefit of secondary and tertiary industries made asymmetric working population and economic benefit, i.e. the primary industry ranks the third in the economic structure, but the actual working population occupies a high number, while the secondary and tertiary industries has a very strong potential for development. Their growth will be far greater than the agricultural growth, but their working population is far less than that of agriculture. Compared the economic benefits between agricultural population and working population in the secondary and tertiary industries, you will find that the benefits of agricultural population is at the bottom layer in the whole society and this is the macro-economic condition of farmer flow.

Secondly, the double squeeze of policy and economy challenges of village living conditions. In the history of our country, the long-term dual gap between urban and rural areas has been in existence. In the early years of founding, the household registration system and political system firmly imprisoned the change in various elements of the village to keep the village topography in a certain extent. Since the beginning of reform and opening up, the changes in the village governance system smashed the firm constraint of micro-political structure to farmers during the period of system of integrating administrative unit with economic entity. Meanwhile, the introduction of a market economy and economic development made the villages become the victim in participants of market economy. China's investment for policies and economy on the secondary and tertiary industries increase the potential for urban development, and indirectly undermine the balance between urban and rural areas. The inevitability of economic restructuring also makes the village in a competitive rural decline. The rural areas squeezed by policy and economic development, gradually lost its unique charm. The benefit and efficiency flow to the cities which makes the villagers to have unique longing. Especially, the implementation of the household contract responsibility system erased the last barrier which imprisons the village and the village cannot protect the original topography any more. Under the integrated promotion of various factors, villagers flow is inevitable.

\subsubsection{Micro causality of farmer flow}

Externalization of the villagers' interests is the inevitable choice of villager flow. After the reforms and opening-up, the implementation of the household contract responsibility system arouses farmers' enthusiasm for production and agriculture shows a steady growth trend. However, with the economic development, agricultural income grows relatively slowly, the price of production materials rises, and the other living costs increases make the original villagers who depend on the agriculture for a living feel the pressure to survive. Thus, going out to earn more incomes seems to be an inevitable trend. Around 2006, this trend became a tide. The villagers can earn more money through leaving their rural hometown to work in cities. Such gains gradually increase with the passage of time and gradually dilute the land revenue. Such dilution exacerbated flow of farmers thus intensifying the farmer flow and finally made most villages of the country present a shell trend. The decline of rural development has become a common problem. This commonality not only fails to ease the flow of farmers, but also becomes a catalyst for this flow, thus the farmers gradually blending in city life in this flow and getting out of the village life and discomfort, especially the new generation of farmers. No land and being unable to farm indicate that farmer flow will develop toward the more general direction. Meanwhile, the traditional concept of land for the guarantee of life has not completely faded from the 
concept of the farmers. The people do not give away land while leaving the rural hometown to work in cities, which is a common notion of farmers. The consequent separation of governance has more significant impact.

\section{Economic change and problems caused by farmer flow}

Development and changes in the economy significantly push forward the peasant migration. Such impetus greatly changes the social pattern. Similarly, farmer flow makes great contribution to economic development and has important influence on pattern of economic development. However, the villager flow is a spontaneous and common behavior of villagers and brings some problems for governance and macro-economic framework of the society. Meanwhile, as the vulnerable group, "migrant workers" is also facing their own survival problems.

\subsection{Economic change}

Firstly, enhance the economic benefit of the secondary and tertiary industries. Adjustment of economic structure indicates that adjustment of the working population. To shift from an agricultural country to an industrial country, the agricultural population will inevitably need to transfer to industry. The vast majority of the population in China is rural population, which is a well known fact. This is an inevitable choice of working population in secondary and tertiary industries. Therefore, the natural population flow from rural area to urban area inevitably accelerates the development of secondary and tertiary industries. A large number of migrant workers in the construction, processing and other low-end industries have made indelible contribution for China's economic development. With their own advantages, they promote the development of secondary and tertiary industries. This is spontaneous evolution of the structural adjustment of China's population and provides a rare human mobility and strength for society transformation.

Secondly, cause the abandoning of primary industry. Flow of a large number of farmers has effectively improved the secondary and tertiary industries, while the gap of labor force emerges in rural area. After the villagers' agricultural income cannot meet their daily lives, migrant workers has become an inevitable choice of farmers and a good way to bridge the income gap. Therefore, under the promotion of farmer flow, the young and middle-aged men from villages became the workers in cities. The women, the elderly and children stay at home for agriculture, especially the new generation of farmers. The highly longing for the city causes the migrant workers to be unable to farm in rural areas. Such demographic patterns lead to the labor shortages in villages and abandon of a lot of land. Meanwhile, the aversion to land of the new generation of farmers has restraining impact on the development of agriculture.

\subsection{Social issues caused by farmer flow}

Perhaps, peasant migration promotes adjustment of larger population distribution, provides new opportunities for the economic development and adjustment of industrial structure and population structure, and makes preparation for the development and change of society. However, the development of the cities and attracting force need further impetus, and flow of a large number of farmers undoubtedly causes some problems with urban development, economic growth rate and social stability.

Firstly, conflict between economic structure and farmers flow direction. Since farmers migration is derived from the decline of agricultural position caused by economic development. This is triggered by allocation of efficiency and resources throughout the society. This is spontaneous in a certain extent. Meanwhile, the common flow of vast majority of the villagers makes the government have no time to attend to the matter. The current flow direction and their occupations are inevitably random. Such randomness inevitably has conflict with the economic structure and direction of economic development, for example, the geographical imbalance in the flow of migrant workers. The migrant 
workers mainly flow into main cities, resulting in congestion of migrant workers. However, medium and small cities also lack human resources for economic production to some extent, thus generating a less efficient farmer flow. Secondly, the unbalanced flow of occupations. Migrant workers in the flow process are generally engaged in low-end physical sectors with easy operation. They have no ability or opportunity to occupy the high-end or mid-end positions. Meanwhile, the industries which they enter are also random. There may be too many migrant works in some industries and too less migrant workers in other industries. In this way, population mobility and economic development are somewhat misplaced, which is not conducive to the reasonable utilization of resources and employment of migrant workers.

Secondly, lack of farmer liquidity and social functions. With economic development and large flows of rural population, farmers gradually enter people's vision as "migrant workers". Due to the household registration system, although the migrant workers live in the cities, they are out of the management of the city and have no citizenship. Their identification is essentially different from that of local citizens. They cannot get appropriate help in social security and employment security. If they are unemployed in the cities, they cannot guarantee their normal life. Meanwhile, because of their inferior status and weak legal consciousness, unpaid wages and other violations often occur, and no relevant mechanisms protect the legitimate rights of migrant workers. Since a large number of migrant workers are outside the urban governance, their basic information and the basic situations are not recorded effectively and their overall situation of migrant workers in the city is low in the urban population, this can easily lead to unexpected events and bring more troubles for governance. However, the great mobility and irregular residence period of migrant workers increase difficulty of statistical work. Besides, the cities also lack appropriate social mechanisms to guarantee the social rights of migrant workers well.

Thirdly, weak development of farmers and villages. During decline in the status of agriculture and social security function of land, the villages which take the land revenue as the center, have gradually lost its most basic reason for existence. The increase of proportion of outside benefits causes the young and mid-aged men to no longer stay in the villages. The young and mid-aged men are the backbone of villages. Loss of such backbones gradually leads to the decline of villages in future competition. The outflow of village elites and backbones leads to lack of necessary and effective strength for village governance and development, thus getting into troubles. In the process of contact with the outside world, the constant flowing villagers become the citizens with participation consciousness, thus having inability to adapt to the original country-side life in all aspects such as behavior and ideas. The existence of such villagers further collapses the village community. Weakening of benefit connection and divergence in ideas and concepts ultimately accelerates disintegration of the villages. Without reasonable restructuring, the villages are unable to develop.

\section{Study on countermeasures}

The farmer migration driven by economic development does not only play a role in promoting economic development, but also make the economic development and the status and income of migrant workers asymmetric, because of its randomness cased by spontaneousness, which poses some problems for economic development and social governance of China. However, it is an inevitable phenomenon for the economic development to drive the farmer flow and a prelude to social change and population differentiation. Facing this inevitable trend, proper guidance and reasonable regulation is essential. On one hand, this can overcome the governance conflicts caused identity and randomness of migrant workers; on the other hand, this can overcome the influence of mobility of a large number of farmers on village development.

\subsection{Dynamic management of population promotes dynamic social function}

Economic development triggers massive outflow of migrant workers, which is the largest mobility group. According to their needs, they moves among the major cities and have no fixed residence and 
stable jobs, a large number of floating population makes most of the villagers out of the constrain of governance system and detach from governance to become the groups without regulations and various social rights. Their group disassociation can easily lead to a variety of unexpected conflict and pose potential threat to urban governance. Therefore, dynamic population management system is very important. The author believes that the dynamic population management system is different from past urban and rural household registration system. The past household registration system is stable and unique, which cannot integrate with the mobility of migrant workers. Thus, dynamic population management system is very important. We can establish such a platform to manage groups of dynamic and free migrant workers and grant flexible rights to this platform, provide a variety of social security for migrant workers, and manage the floating migrant workers with advanced management methods and technologies. On one hand, this guarantees the various social interests of migrant worker groups; on the other hand, this can provide powerful debugging for migrant workers in all aspects, orderly organize migrant workers and thus bring about social stability.

\subsection{Creating guidance platform and adjusting employment and the economy}

Migrant workers are from the countryside. Their living environment is quite different from that of colorful city. Their own strength and economic development are considerably dislocated, thus causing villagers' discomfort and longing for city life. The mutual asymmetry between their own strength and economic development leads to failure of migrant workers to get their due reward through reasonable labor, and all kinds of discomfort increase the unhappiness of migrant workers. Therefore, it can be considered to establish a guidance platform for villagers to provide various jobs, life, business and other information to allow the migrant workers to be kept informed of changes in information in order to make their own choices. Meanwhile, a variety of inputs (such as the creation of social organizations, job skills training of migrant workers, working and living experience) are provided to cultivate the migrant workers reasonably, to allow the migrant workers to reasonably and efficiently work and to save the appropriate human resources.

\subsection{Revitalizing rural resources and enhancing the competitiveness of the village}

Mobility of farmers is the inevitable result of economic development, but mobility of too much farmers brings problems with governance for the society and it is also an important reason for the recent decline of the village. On the current level of urbanization in our country, the population flow degree and range have been far beyond absorptive capacity of the city. The overcrowding of urban population cannot achieve effective transfer of resources. Therefore, it is unwise to only manage the floating population. On one hand, the difficulty of management increases; on the other hand, the excessive floating population still cannot be properly resettled. It would be better to shift the viewing angle to the countryside itself and revitalize all kinds of resources in rural areas, to allow the villagers to earn their own gains for survival and development in the villages. On one hand, this can ease various contradictions and conflicts caused by farmer flow; on the other hand, the decline of the villages can be interrupted to absorb more labor, and effective reduce the floating population. Similarly, this strategy is the basic idea of reform experimental zone of property rights throughout the country and helps to keep our environment stable as a whole.

\section{Acknowledgement}

This paper is supported by general project for 2011 supported by National Social Science Foundation: Study on Property Right Reform of Rural Collective Construction Land and Transformation of Grass-root Social Governance (GN: 11BZZ060) 


\section{References}

1. Fei Xiaotong, Earthbound China, Reproductive System [M], Beijing: Peking University Press, May 1998, page 24.

2. Proportion of tertiary industry during "eleventh five-year plan increases to $443 \%$, with an increase of 2.5\%" [DB /OL]

3. Xu Yong Unbalanced China Politics- Comparison

4. between Urban and Rural [M]. China Broadcast TV Publication, June, 1992. /OL]. China News, March 11, 2011. 